\title{
Exotics
}

5. Which of the following statements is correct with regard to excessive egg laying in parrots?

a. Surgical removal of the oviduct will guarantee cessation of ovarian activity and should therefore be considered as the preferred treatment option

b. Excessive egg laying is predominantly seen in psittacine species that belong to the group of indeterminate layers c. Shortening daylight (8L:14D) and removal of nest boxes and nesting materials will usually be sufficient to stop egg laying in parrots from equatorial regions

d. Medroxyprogesterone is considered a safe and effective treatment for parrots with excessive egg laying
Review of common diseases of ornamental fish

\section{Peter Scott}

The keeping or ornamental fish in aquaria and ponds is an extremely popular hobby with a long history. The supply of fish has evolved over the years and is extremely professional in handling of the fish involved, which often travel great distances around the world. The associated 'technology' for maintaining the fish has also developed considerably.

This session will briefly outline the numbers and supply routes of ornamental fish, the structure of the UK industry and the controls which must be in place to protect native populations from imported disease.

The various common diseases, viral, bacterial, protozoal, metazoan, fungal and non-infectious, which may be seen in pondfish and in aquaria will be illustrated and appropriate treatment options will be discussed. The pathogenesis of disease in the captive situation will be discussed and what measures can be taken to reduce problems. Although not 'common', notifiable disease will be covered.

\section{KEY LEARNING OBJECTIVES}

To gain an understanding of the pet fish industry To be aware of the common diseases of pet fish To be able to understand the problems seen in pet fish and contribute towards the solutions

\section{MULTIPLE CHOICE QUESTIONS}

1. What are the most commonly seen diseases of ornamental fish?
a. Viral
b. Bacterial
c. Protozoal
d. Endemic

2. Monogenean flukes are commonly found in which parts of the body?
a. Skin and gill
b. Gut
c. Kidney
d. Eyes

3. What is fishkeeper's finger or aquarist's arm caused by?
a. Mycobacteria sp
b. Erisipelothrix $\mathrm{sp}$
c. Streptococcus sp
d. Digenean trematodes

4. Which of these is not true?
a. Use of antibiotics via the water is bad practice
b. Malachite green has been banned for use in fish
c. Ich is the most important disease of captive fish worldwide
d. Fish are excluded from the Veterinary Surgeons Act

5. Which treatment aspect is not a common part of routine therapy of ulcers on individual koi?
a. Antibiotics by injection or food
b. Debridement and barrier products
c. Approx. $5 \mathrm{~g}$ of salt per litre in quarantine or the pond
d. Antibiotics in the water in quarantine or the pond

\section{Getting diagnostic samples and understanding water quality}

\section{Peter Scott}

There are two areas for testing in investigating fish health: these are the fish and their environment.
Fish can be anaesthetised, radiographed and submitted for computed tomography (CT) or magnetic resonance imaging (MRI) scanning.

Blood samples and biopsy samples can be taken, even laparoscopically. Postmortem investigation is routine and valuable: fish autolyse extremely rapidly so the use of remote laboratories is limited in this regard. Practitioners need to be aware of techniques and appropriate sampling.

Gill and skin scrapings are routine tasks examining for common parasites; these can be carried out on live fish, anaesthetised fish or indeed at postmortem. Histopathology and bacteriology can be very valuable if the correct samples are taken. Specialist virology is also available.

Captive fish are totally dependent on keepers to 